\title{
Research on Orphan English Teaching from the Perspective of Emotional Education
}

\author{
Binbin $\mathrm{Fu}^{1}$ \\ ${ }^{1}$ Foreign Linguistics and Applied Linguistics, College of Tourism, Hainan University, Haikou, 570203, China
}

Keywords: Affectional education, Emotional education, Orphan English

\begin{abstract}
Strengthening emotional education for orphans is an important task in the construction of modern harmonious society. Emotional education is a part of the education process, which pays attention to the attitude, emotion and belief of the orphan students in the whole education process and promotes the healthy growth of the orphan students. This paper analyzes the importance of affective education in orphan English education, and gives orphan English teaching strategies from the perspective of affective education, including respecting orphan students, excavating emotional factors, stimulating learning interest and innovating teaching models to provide some references for relevant researchers.
\end{abstract}

\section{Introduction}

How to educate orphans is the most important problem for teachers who are engaged in orphan education [1]. The study of psychology shows that any knowledge activity is carried out under the motive force of emotion. Thus, the emotion of the learner is an important part of the educational goal. The new curriculum standard clearly points out that the aim of the new curriculum is to cultivate children's interest in learning English, to master simple English knowledge and to use English skills, to develop communicative activities and to understand the differences between Chinese and Western cultures, and to develop interest in learning English gradually to the interest of learning, and to cooperate with others to develop a healthy and harmonious quality. Especially when we are faced with a group of special educational objects orphans, we should make better use of emotional education. Because of the special background, the young and young children of the orphan students have been suffering from the frustrations and hardships of the world too early. The outstanding external manifestations of the school are the self-abased and floating of different degrees, the weariness of learning and the unwillingness to make progress. In terms of learning, orphan children are weaker than those of normal families, especially in English subjects. Germany will become dull and empty words, and only cultivate hypocrites. Orphan children have been heavily injured in a certain stage of their lives, so it is more important to educate their children in a comprehensive and harmonious way at the stage of education. Educational psychology believes that in the scenario of education, the interactive emotional relationship is the key for students to achieve academic success and achieve the goal of education. It is the core and soul of education management to establish a people-oriented concept and promote the all-round and coordinated development of every student. Every link of education management, the use of every method, and the implementation of every decision should reflect and contain the factors of education and promote the all-round and harmonious development of the students [2].

\section{Significance of Emotional Education in Orphan English Teaching}

Due to the special growing environment, most orphaned students are isolated, self-abased, and unwilling to communicate with people [3]. They are incompatible with the world, have no emotional support, have no confidence in life, do not think enterprising, feel that they are forgotten by the world and cynical. Special education are generally difficult to approach its life, not to mention the teaching. 
In our special education teacher just contact to these students, basically no verbal communication. A special educator is faced with the weakest and most difficult orphan group in the world. The emotion of the orphans in the early and high school is accompanied by the trauma of childhood, the loneliness of the young and the forthcoming of the adult. It is of great significance for the lifelong development to give positive and effective emotional education to the orphans. The orphan students are a special group of social concerns. They are out of the way and do not know how to care for others. This is understandable. Our purpose is to carry out a sound personality education for them, to erase the pain in the heart, and to make them feel love in life. Emotional education is an important goal of mental health education curriculum standard. Curriculum objectives include three aspects, one of which is emotion, attitude and values. The goal of realizing the curriculum of mental health education is to carry out the process of emotional education, which should be learned by every special teacher, and learn to take the students as the center and highlight the value of the students. Emotional education is an effective way to cultivate orphan students. The orphans' physiology and psychology are mature and their ideological consciousness is easily influenced by many factors. Therefore, it is easier for them to do emotional education at this age stage, especially for the female orphans. They are easy to approach, and they are more likely to accept the instilled things to change their thinking.

\section{Current Situation of Emotional Education Application in Orphan English Teaching}

At the present stage, some teachers emphasize English knowledge and achievements one by one, but don't attach enough importance to emotional education. Influenced by the traditional education concept, some junior high school English teachers are conservative and cannot keep pace with the times. They still regard the achievement as the only condition to evaluate the good and bad of an orphan student, neglect the other abilities of the orphans and neglect the emotional education of the orphans. Junior middle school students are at the critical stage of puberty development. Teachers need to care and love them, so as to promote their healthy growth and healthy personality formation. Due to the lack of emphasis on emotional education in junior high school English teachers, it usually spends a lot of time on the explanation of English words and texts, and the free time of the orphans students is few, which seriously hinders the students' desire for learning and learning enthusiasm, which is not conducive to the smooth progress of English classroom teaching. Some teachers' understanding of emotional education is not comprehensive. Because of the different qualities of junior high school English teachers, there are some English teachers who have not thorough understanding of emotional education, but only one-sided understanding of emotional education. In English teaching, it does not play the practical role of emotional education and causes confusion in English teaching. Although English has realized that it is necessary for orphans and students to learn happily in the classroom, they have not been able to get rid of the teachers' ideas. In class, only the students' English scores are ignored in the classroom, and the training of the practical ability of the orphan students' English is ignored, thus the cognitive and emotional separation of the junior high school students will affect the English learning. Junior high school students are the best time to accept emotional education, so English teachers must improve their own quality, understand the significance of emotional education and combine English teaching with emotional education [4].

\section{Strategies of Orphan English Teaching from the Perspective of Emotional Education}

\subsection{Respect Orphan Students}

Respect is an important prerequisite for the education of orphan children. For them, teachers should love twice as much. In the process of growing up, students can't have no motherly love, but they are not orphans. Most of them because of family reasons, more or less will delay a number of courses, poor foundation, easy to abandon themselves, they always close themselves up, feel not the care of teachers, in the long time the emotion of antagonism with the teacher. To transform them, we should turn the cold teacher-student relationship into a warm and intimate teacher-student 
relationship, or further speaking, we are their half parents. If teachers do not love them passionately, it is difficult or impossible to teach them well. Teachers should fully believe in the possibility of students' development in teaching, and people have different aspects and different levels of talents. The special growth experience of the orphans students makes them form a strong inferiority complex, which is manifested in class, that is, there is no enthusiasm in class, passive acceptance of knowledge, not active participation. In classroom teaching, as a teacher, we should enter the classroom with a happy mood. A sincere smile will make every student feel a sunshine. Teachers can make use of hint, euphemistic reminding, small games, singing English songs, text plays or use of teachers' expressions and gestures to make the classroom conducive to the teaching order and atmosphere. Teachers can give full play to their personal characteristics and combine the specific conditions of the students to choose appropriate methods to organize activities. Teachers should fully believe in the possibility of students' development in teaching, and people have different aspects and different levels of talents. For them, we need to help them find their strengths, help students succeed, improve their self-esteem and self-confidence, and be more good at caring and encouraging them.

\subsection{Excavate Emotional Factors}

Teaching materials are the blueprint and basis of teaching. There are rich emotional factors in the content. Teachers need to dig up the teaching materials in depth, find out the parts of the orphan students' life which are closely related to the life of the students and carry on the emotional infiltration, and properly integrate into the teaching process and give the students the full inner feeling experience and the spiritual world growth. In the above cases, teachers can excavate from the perspective of Chinese traditional culture that they need to be grateful for the sensibility of the elders in the process of growth, and from the angle of the Western parents to educate their children to face the difficulties from their childhood. Chinese and Western cultural factors in English textbooks are closely related to students' life experience, and can help orphans to form positive emotions. The teacher's encouragement in the eyes, the mood of appreciation, the smile on the face, the gestures of the touch, the warm applause, or the special gesture of the body, can also play an incentive to the students. Because all of these are expressing information to students. Because of love, we become friends with orphan children and become relatives. To help them find their strengths, help their students to succeed constantly, improve their self-esteem and self-confidence, be better at caring and encouraging them, catching their glittering points and giving them affirmation and praise in time to let them know that teachers have not forgotten them. In fact, every student has their ideals and ambitions, but they are dilute because of various reasons. Orphan children have experienced the tragic transition of life. Therefore, teachers must guide them to acquire the psychological self-hint effect that can be realized in the successful trap of the teachers, and then create self-confidence, and feel that as long as they try hard, they can fully realize their aspirations.

\subsection{Stimulate Learning Interest}

Interest is a tendency for individuals to know objects and strive for knowledge. Daily work, learning and life reflect the great role of interest. Interest is a power source that provides motivation and energy for learning, work and life. Steady interest can urge people to learn, work and live continuously and efficiently. The level of language knowledge. Their weak basic knowledge of English requires teachers to pay more attention to their original knowledge base when they teach declarative knowledge and to help them to supplement the level of complement language skills. Their low English skills require teachers to consider the low starting point of orphans and give orphans the opportunity to do things in English in class when they design variant exercises and give feedback in the process of teaching procedural knowledge. Emotional level. The fragile psychology of orphans needs teachers' special care. Learning strategy level. Their poor academic knowledge requires the teaching teachers to give specific guidance to the teaching of knowledge, including pre class preview, classroom behavior, review after class, homework treatment, extracurricular practice and examination techniques. The level of cultural consciousness. Because of their lack of cultural knowledge and cultural awareness due to language barriers, teachers need to pay attention to the 
infiltration of cultural elements in classroom teaching. To meet the needs of English orphans in class. Teachers guide them to prepare knowledge for class. Teaching practice shows that students are not interested in what they do not understand. It helps students find their own advantages, experience success and enhance self-confidence. In the question and answer practice of the teacher and the individual student, many students cannot get back to the question, or answer the questions inaccurately, thus losing their interest in learning and losing their confidence in learning English. In a setback experience, it brings irrevocable negative effects to students. Group cooperative learning can solve this problem, depending on the task that cannot be accomplished by a single person. Therefore, knowledge preparation is the basis for interest production. The preparation of English knowledge is expressed in all aspects, and here is only the processing of new words as an example. When arranging homework in class, teachers should clarify the scope of new words involved in next class and put forward specific preparation requirements. At the beginning of the new lesson, teachers should arrange time to check the preview of new words for orphans, and help students to clear up the new words obstacles in the lesson.

\subsection{Innovate Teaching Models}

In the past, the traditional teaching mode overemphasized the students' learning of knowledge and skills. Under the guidance of cognitive goals, the tendency of knowledge standard was serious, and the infiltration of emotion was dispensable. This teaching mode fundamentally leads to students' lack of emotion and the loss of their overall concern for the all-round development of human beings. Therefore, the modern teaching mode should pay attention to the three unity of knowledge, skill and emotion. In the course of teaching, teachers should not only pay attention to the students' acquisition of language knowledge, but also pay attention to the development of their emotions, and realize the true emotional communication with the students. A good orphan teacher and math teacher should know how to care for students and enter their mental world. We should guide them to build up their lofty ideals and goals. We should be good at using humorous language, vivid metaphors, interesting examples and different classroom situations to stimulate their interest in learning, improve their self-awareness of learning mathematics, and ultimately achieve the purpose of transforming their learning enthusiasm. The future education must not only be satisfied with the students' knowledge and skill. Through the complement of the members of the group and the influence of the good students, the students who think the results are not correct can be corrected in time. The interest in learning English will increase greatly and improve the enthusiasm of learning English. It must put the students in a living and living body with personality and potential, develop their creative potential, stimulate their creative spirit, constantly improve their life quality and survival value, so that they can really adapt to the society, dare to challenge the society, and eventually become the society. The teacher should flexibly borrow the teaching media equipment, such as slide machine, projector, computer multimedia and use simple gestures language and spoken English to organize the classroom teaching content. In a language environment conducive to English learning, the boring and monotonous content is vivid, image and interesting. The combination of teaching scenarios makes English teaching process lively and interesting.

\section{Conclusion}

Orphans are a disadvantaged group in our country. As the English teachers, we should take the orphan students seriously to carry out a sound personality education, add color to the orphan students' lives, and let them be full of expectations for the future. English educators should integrate emotional education into teaching, helping orphans to become active, open minded, virtuous and highly capable social talents. 


\section{References}

[1] Guo Yanan. An Analysis of Middle School Students' English Learning Motivation [J]. English on Campus, 2017(11): 181.

[2] Zhang Chao, Rao Xiaoli. Research on the Application of Emotion Facts in Improving English Ability of Vocational College Students [J]. Journal of Hubei Radio \& Television University, 2017, 37(3): 21-25+39.

[3] Chang Fang. The Construction of Cognitionand Emotion Education Mode Centeredon College English [J]. Journal of Dalian Nationalities University, 2010, 12(2): 190-192.

[4] Yan Danpin, Zhao Lizhu. The Practice Research of Emotion Education Application in College English Layered Teaching [J]. Journal of Hubei Correspondence University, 2017, 30(11): 144-146. 